\title{
Assessment of Physico-chemical Parameters of Soils in Fallowing Farmlands and Pit Toilet Environments as it Affects the Abundance of Geohelminthes in Emohua Local Government Area, Rivers State, Nigeria
}

\author{
Owhoeli Ovutor $^{1 *}$, Imafidor Helen ${ }^{1}$ and Grace D. B. Awi-waadu ${ }^{1}$ \\ ${ }^{1}$ Department of Animal and Environmental Biology, University of Port Harcourt, P.M.B. 5323, Choba, \\ Port Harcourt, Rivers State 500001, Nigeria.
}

\section{Authors' contributions}

This work was carried out in collaboration between all authors. Authors OO and GDBAW designed the study and wrote the first draft. Authors $\mathrm{IH}$ and $\mathrm{OO}$ managed the analyses and literature searches. All authors read and approved the final manuscript.

Article Information

DOI: $10.9734 / A R R B / 2017 / 31546$ Editor(s):

(1) Paola Angelini, Department of Applied Biology, University of Perugia, Perugia, Italy. (2) George Perry, Dean and Professor of Biology, University of Texas at San Antonio, USA.

Reviewers:

(1) Abdullahi Yahaya, Kano University of Science \& Technology, Nigeria.

(2) Aniwada, Elias Chikee, University of Nigeria Enugu Campus, Nigeria. (3) J. Siwila-Saasa, University of Zambia, Zambia. Complete Peer review History: http://www.sciencedomain.org/review-history/19915

\begin{abstract}
Background: This study was conducted to determine the effects of physico-chemical parameters of soils in environments used for open defecation on the abundance of geohelminths in Emohua, Rivers State, South South, Nigeria.

Methods: A total of 720 soil samples were collected randomly from soils found in fallowing farmlands used for open defaecation and around pit toilet environments in Mgbuitanwo, Isiodu, and Rumuche Communities in Emohua local Government Area of Rivers State. Two hundred and forty samples were collected randomly from each of the communities between the months of JanuaryJune 2013 and 2014 respectively. The samples were analysed for temperature, $\mathrm{pH}$, and organic content and Centrifugal flotation method was used to examine the samples for geohelminths.
\end{abstract}


Results: Evaluation after two variations gave an average of $198(55 \%)$ of the soil samples as positive for geohelminths as follows; $16(4.4 \%), 131(36.3 \%)$ and $51(14.1 \%)$ for clayey, loamy and sandy soils respectively. This was statistically significant $(p<.05)$. Results also showed soil temperature mean $27.2^{\circ} \mathrm{C} \pm 5.2 \mathrm{~S}$.D, soil $\mathrm{pH}$ mean $6.3 \pm 2.5 \mathrm{~S}$.D and soil organic matter mean $12.7 \% \pm 3.6$ S.D, clay soil mean $16 \pm 4$ S.D, loam soil mean $115.5 \pm 10.7$ S.D and sandy soil mean $47.5 \pm 6.9$. The geohelminths recovered from the samples were 293 as follows; Clayey: $25(8.5 \%)$, Loamy: 189(64.5\%) and Sandy: 76(26\%). Ascaris lumbricoides 92(31.4\%), Trichuris spp. 55(19.5\%), Ancylostoma duodenale 38(12.9\%), Strongyloidies spp. 12(4\%), Entrobius spp. 10(3.4\%), Trichostrongylus spp. 5(1.6\%), Schistosoma mansoni 2(0.6\%), Meloidogyne spp. 48(16.4\%), Radopholus spp. 1(0.3\%), Aphelencoidies spp. 1(0.3\%), Bayliascaris spp. 5(1.7\%), Toxocara spp. 21(7.2\%) and Ancylostomacanis 2(0.6\%).

Conclusion: Due to the presence of human, plant and animal infecting geohelminths in the area, the Government should reintroduce sanitary inspection of our environments to check the indiscriminate and unhygienic disposal of human waste.

Keywords: Emohua; environments; geohelminths; soils.

\section{INTRODUCTION}

Geohelminthes are soil-transmitted parasitic nematodes with lifecycle that involves no intermediate host or vector and are among the most prevalent of chronic human, animals and plants infections worldwide [1]. They are spread by faecal contamination of soil, foods and water, wind and agricultural machinery. You find them in almost all habitats, but are most times overlooked because majority are microscopic in nature [2]. Soil is an excellent habitat for nematodes; a handful of soil may contain several of them [3]. Geohelminthes premature stages (eggs) require a period of development in the soil before they become infective [4]. In 2010 it was estimated that about 1.45 billion people in the world were infected with Soil-Transmitted Helminthes (STHs) and 5.19 million showed associated morbidity [5,6]. Out of 1.45 billion infections due to Soil Transmitted Helminths, 438.9 million were infected with hookworm (Ancylostoma duodenale and Necator americanus), 819 million with Ascaris lumbricoides and 464.6 million with Trichuris trichiura and 4.5 billion people at risk of infection with one of the three common soiltransmitted helminths above [6,7]. Majority of the people infected with soil transmitted helminthes are school-aged children from rural communities of sub-Saharan Africa, a region characterized with favourable environmental and human factors that enhance parasite transmission $[8,9]$. Damage caused by plant nematodes has been estimated at about $\$$ US80 billion per year [10]. However, this is likely to be a significant underestimate of the true figure, because many farmers, particularly in developing nations, are not aware of the existence of plant- parasitic nematodes, as a result of their usual small nature and most times losses from their nonspecific effects are misconstrued to be loss from other pathogenic organisms or certain environmental factors [11,12]. All crops grown inNigeria are prone to nematode attack, causing farmers' significant crop loss annually [13]. The infection is promoted by poor hygienic habits such as indiscriminate disposal of human and animal faeces.

In Nigeria, a large amount of human and animal waste is discharged into the soil daily leading to the seeding of the soil with pathogenic organisms including geohelminthes eggs and larvae [14]. This permits contact with faeces and its accompanying microbial load including geohelminthes eggs in the soil. Other risk factors include lack of safe drinking water source, poverty, geophagia, and having pools of water or sewage around the house $[15,16]$. Soil factors influencing the helminth communities include nutritional environment, carbon conservation and physical changes to the soil structure caused by agricultural operations [17]. Experimental studies suggest that the maximum temperature for the development of $A$. lumbricoides and Trichuris trichiura is between $5^{\circ} \mathrm{C}-38^{\circ} \mathrm{C}[18,1]$, while the development of hookworm larvae ceases at $40^{\circ} \mathrm{C}$ $[19,20,1]$. It is suggested that $A$. lumbricoides eggs are more resistant to extreme temperature than Trichuris eggs [21]. Furthermore, soil moisture and relative atmospheric humidity are also known to influence the development and survival of eggs and larvae. Higher humidity is associated with faster development of ova and at low humidity ( $<50 \%)$, the ova of $A$. lumbricoides and Trichuris trichiura do not embryonate [22]. Field studies show that the abundance of 
hookworm larvae is related to the atmospheric humidity [23].

This study was conducted to determine the effects of physico-chemical parameters of soils in environments used for open defecation on the abundance of geohelminths. The information will not only help in better understanding of geohelminths distributions, but also to serve as geographic decision-making tools for identifying areas at risk as well as for the design, implementation and monitoring of soil environment control programmes by health organizations.

\section{MATERIALS AND METHODS}

\subsection{Study Area}

The study was conducted in Emohua Local Government Area of Rivers State Nigeria. Its headquarter is in the town of Emohua. It is located at 453 ' 0 " North 652 ' 0 " East of the Greenwich. It has an area of $831 \mathrm{~km}^{2}$ (321 sq mi) and a population of 201,901 at the 2006 census [24]. The area lies within the tropical rain forest vegetation zone and inhabitants are mostly traders and farmers. Emohua features a tropical monsoon climate with lengthy and heavy rainy seasons and very short dry seasons with an average temperature range of $26^{\circ} \mathrm{c}$. Three Communities; Isiodu, Mgbuitanwo, and Rumuche, were selected for this research. These communities were selected based on their defecation patterns; where fallowing farmland and Pit toilets are used as toilets. Samples were collected monthly from each of the study sites between the months of January- June 2013 and 2014.

\subsection{Ethical Clearance for the Study}

Permission to conduct the study was got from the community heads. During routine visits to the community heads, the relevance of the study was explained. The community heads further assembled their subjects and explained same to them.

\subsection{Collection of Soil Samples}

Sample collections were done in the morning from about 6am - 12 noon when the larvae and eggs of geohelminthes are still active. Sterile soil auger was used to collect $15 \mathrm{~cm}$ topsoil from randomly selected points. An average of 60 samples was collected each month. The soil samples collected were kept in sterile black polythene bag and taken back to the Animal and Environmental Biology laboratory for analyses.

\subsection{Examination of Soil Samples}

\subsubsection{Temperature}

The temperature of the soils was tested with thermometer during sample collection using ClimeMET CM3011 Soil Thermometer [1].

\subsubsection{Measurement of soil $\mathrm{pH}$}

The reference electrode of the corning $\mathrm{pH}$ meter was inserted into the top $1 \mathrm{~cm}$ of the moist soil surface. The knob of the $\mathrm{pH}$ meter was switched on for about 30 seconds and the value of $\mathrm{pH}$ meter recorded. Later, the reference electrode was rinsed with distilled water that was taken to the site from the laboratory between each soil sample reading. After the reading, the knob of the $\mathrm{pH}$ meter was switched off [1].

\subsubsection{Soil texture}

The field method of using hand was employed to determine the soil texture according to [25].The sand content was determined by rubbing a small amount of soil in the palm of the hands to determine if sand is under or over $50 \%$, if the sand content is less than $50 \%$, water is to be added to create a soil that is wet enough to roll. The soil was squeezed between the thumb and forefinger to make the longest ribbon possible, a loam soil will form only a short ribbon, while a clay soil will form a much longer ribbon.

\subsubsection{Determination of organic matter in the soil}

The organic matter (carbon) was determined by ashing a 5 gram scoop of the soil sample at $360^{\circ} \mathrm{C}$ for 2 hours in a muffle furnace. The loss by weight of the sample during this ignition is calculated as the organic matter. Results are reported as percent organic matter by weight in the soil [26].

\subsection{Examination of Soil Samples for Eggs and Larvae of Geohelminthes}

\subsubsection{Centrifugal flotation method}

The soil samples were sieved using a fine sieve (Pore size $250 \mu \mathrm{m}$ ) so as to remove larger particles but also allow passage of small size 
particles including helminth eggs. From the sieved portion, $2 \mathrm{~g}$ of soil was collected and placed into a $10 \mathrm{ml}$ test tube containing $3 \mathrm{ml}$ of $30 \%$ sodium hypochlorite solution, the test tube was shaken intermittently then $5 \mathrm{ml}$ of concentrated saccharine solution (1000 g of white sugar in $900 \mathrm{ml}$ of distilled water) was added to the test tube and then put in the centrifuge (model HW236) and was set to centrifuge at $1500 \mathrm{rpm}$ for 15 minutes. After the 15 minutes timer is out, the test tubes were removed from the centrifuge and more saccharine solution is added to raise the meniscus and float the eggs. Cover slips were put on the top of the test tubes and wet them by the surface of the floating solution after allowing standing for 15 minutes. The cover slips were carefully removed from the top of the test tubes and gently placed on microscope slides, the slides were examined microscopically for presence of helminths larvae or eggs.The cover glasses were carefully removed from the top of the tubes and placed on microscope slides, the slides were examined microscopically at $40 x$ magnification for the presence of helminthes eggs/ova [27]. The eggs and larvae ofhuman helminths were identified with reference to Atlas of Parasitology [28]. Plant nematodes were identified using atlas on identification of plantparasitic nematodes [29].

\subsection{Data Analysis}

Results obtained from the samples were entered into Ms. Excel 2007 and analyzed using standard deviation and one way analysis of variance (ANOVA) statistical tool was used to assess significant differences in prevalence of geohelminthes. Descriptive statistics were calculated and presented in form of tables [30].

\section{RESULTS}

An average total of 360 soil samples of different textural classes were examined during the study period for geohelminths. One hundred and ninety-eight 198 (55\%) were positive as follows; $16(4.4 \%), 131,(36.6 \%)$ and 51 (14.1\%) for clay, loamy and sandy soils respectively. Thirty-seven $(61.6 \%)$ of the samples were positive in Mgbuitanwo 1 as follows; 4 (6.6\%), 24 (40\%) and $9(15 \%), 37(61.6 \%)$ of the samples were positive in Mgbuitanwo 2 as follows; 1 (1.6\%), 27 (45\%) and $9(15 \%), 34(56.6 \%)$ of the samples were positive in Isiodu 1 as follows; 1 (1.6\%), 21 (35\%) and $12(20 \%), 35(58.3 \%)$ of the samples were positive in Isiodu 2 as follows; 3 (5\%), 24 (40\%) and $8(13.3 \%), 29(48.3 \%)$ of the samples were positive in Rumuche 1 as follows; 6 (10\%), 14 $(23.3 \%)$ and $9(15 \%), 26(43.3 \%)$ of the samples were positive in Rumuche 2 as follows; 1 (1.6\%), $21(35 \%)$ and $4(6.6 \%)$ for clay, loamy and sandy soils respectively (Table 1$)$.

An average total of 360 soil samples made up of clay, loam and sand collected during the study period in Emohua had physico-chemical properties as follows; $27.2^{\circ} \mathrm{C}, 6.3$ and 12.7 for temperature, $\mathrm{pH}$ and \%organic matter with a total of 293 geohelminths were recovered from the samples as follows; Ascarislumbricoides 92 (31.4\%), Trichiuris spp. 55(19.5\%), Ancylostoma duodenale 38 (13\%), Strongyloides spp. 12 (4\%), Enterobius spp. 10 (3.4\%), Trichostrongylus spp. 5 (1.7\%), Schistosoma mansoni 2 (0.7\%), Meloidogyne spp. 48 (16.4\%), Radopholus spp. 1 (0.3\%), Aphelencoides spp. 1 (0.3\%), Bayliascaris spp. 5 (1.7\%), Toxocara spp. 21 $(7.1 \%)$ and Ancylostoma canis 3 (1.0\%). Physico-chemical parameters of clay soils were $26.5^{\circ} \mathrm{C}, 6.5$, and $10.7 \%$ for temperature, $\mathrm{pH}$ and \%organic matter with a total of 25 (8.4\%) geohelminths recovered as follows; Ascaris lumbricoides 9 (36\%), Trichiuris spp. 8(32), Ancylostoma duodenale 2 (8\%), Meloidogyne spp. 4(16\%), Bayliascaris spp 1(4\%) and Toxocara spp 1(4\%). Physico-chemical parameters of loam soils were $27.5^{\circ} \mathrm{C}, 6.2$, and $14.9 \%$ for temperature, $\mathrm{pH}$ and \%organic matter with a total geohelminths of $189(64.5 \%)$ recovered as follows; Ascaris lumbricoides 58 (30.6\%), Trichiuris spp. 32(16.9\%), Ancylostoma duodenale 26 (13.7\%), Strongyloidesspp. 10 (5.2\%), Enterobius spp 9(4.7\%), Trichostrongylus spp. 4(2.1\%), Schistosoma mansoni 2(1\%), Meloidogyne spp. 28(14.8\%), Radopholus spp. 1(0.5\%), Aphelencoides spp. 1(0.5\%), Bayliascaris spp. 4(2.1\%), Toxocara spp.13 (6.8\%) and Ancylostoma canis 1 (0.5\%), while Physico-chemical parameters of sandy soils were $27.7^{\circ} \mathrm{C}, 6.3$, and $12.6 \%$ for temperature, $\mathrm{pH}$ and \%organic matter with a total of $79(27 \%)$ as follows; Ascaris lumbricoides 25(31.6\%), Trichiuris spp. 15(18.9\%), Ancylostoma duodenale 10(12.6\%), Strongyloides spp. 2 (2.5\%), Enterobius spp. 1(1.25\%), Trichostrongylus spp. 1(1.25\%), Meloidogyne spp. 16 (20.2\%), Toxocara spp. 7(8.8\%) and Ancylostoma canis 2 (2.5\%). See Table 2.

Soil temperature mean $27.2^{\circ} \mathrm{C} \pm 5.2 \mathrm{~S}$.D, soil $\mathrm{pH}$ mean $6.3 \pm 2.5$ S.D and soil organic matter mean $12.7 \% \pm 3.6$ S.D, clay soil mean $16 \pm 3.5$ S.D, loam soil mean $115.5 \pm 10.7$ S.D and sandy soil 
mean $47.5 \pm 6.9$. Loamy soil had highest number of 233 samples, sandy soil had 95 samples, and clay had 32 samples. See Table 3.

Out of the two hundred and ninety-three geohelminthes recovered during the study period, 155 (52.9\%) was recovered between the months of January- March with physico-chemical parameters as follows; $27.7^{\circ} \mathrm{C}, 5.9$ and $14 \%$ for temperature, $\mathrm{pH}$ and \%organic matter while 138 $(47.1 \%)$ was recovered between the months of April-June with physico-chemical parameters as follows; $26.3^{\circ} \mathrm{C}, 6.7$ and $12.2 \%$ for temperature, $\mathrm{pH}$ and \%organic matter (Fig. 1).

Table 1. Prevalence of geohelminths in the soil types of the study area

\begin{tabular}{llllll}
\hline Sampling sites & $\begin{array}{l}\text { Average } \\
\text { no. of soil } \\
\text { sampled }\end{array}$ & \multicolumn{2}{c}{ Soil types positive for geohelminthes (\%) } & $\begin{array}{l}\text { Total no. of soils } \\
\text { positive for } \\
\text { geohelminthes (\%) }\end{array}$ \\
\cline { 3 - 5 } & 60 & $4(6.6)$ & $24(40.0)$ & $9(15.0)$ & $37(61.6)$ \\
\hline Mgbuitanwo 1 & 60 Samy & $27(45.0)$ & $9(15.0)$ & $37(61.6)$ \\
Mgbuitanwo 2 & 60 & $1(1.6)$ & $21(35.0)$ & $12(20.0)$ & $34(56.6)$ \\
Isiodu 1 & 60 & $1(1.6)$ & $24(40.0)$ & $8(13.3)$ & $35(58.3)$ \\
Isiodu 2 & 60 & $3(5.0)$ & $14(23.3)$ & $9(15.0)$ & $29(48.3)$ \\
Rumuche 1 & 60 & $6(10)$ & $21(35.0)$ & $4(6.6)$ & $26(43.3)$ \\
Rumuche 2 & 60 & $1(1.6)$ & $131(36.3)$ & $51(14.1)$ & $198(55.0)$ \\
Total & 360 & $16(4.4)$ & $131)$ & \\
\hline
\end{tabular}

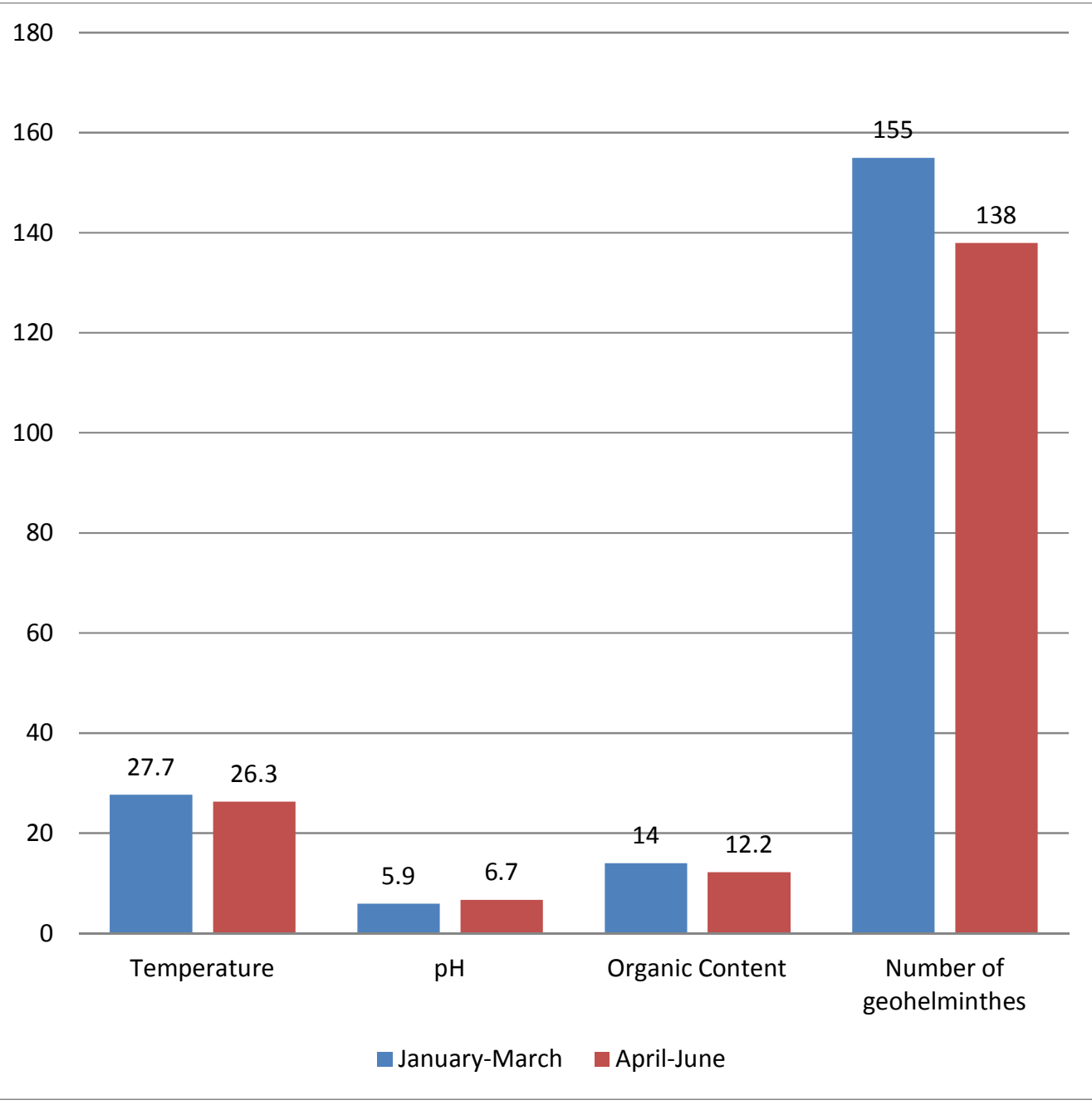

Fig. 1. Temporal variations of Geohelminthes populations in the study area 
Table 2. Prevalence of geohelminths as affected by soil Physico-chemical parameters the in Emohua during the study

\begin{tabular}{|c|c|c|c|c|c|c|c|c|c|c|c|c|c|c|c|c|c|}
\hline $\begin{array}{l}\text { Soil } \\
\text { types }\end{array}$ & $\begin{array}{l}\text { Temperature } \\
\text { (C) }\end{array}$ & $\mathrm{pH}$ & $\begin{array}{l}(\%) \\
\text { organic } \\
\text { matter }\end{array}$ & $\begin{array}{l}\text { Ascaris } \\
\text { lumbricoides }\end{array}$ & $\begin{array}{l}\text { Trichuris } \\
\text { spp. }\end{array}$ & $\begin{array}{l}\text { Ancylostoma } \\
\text { duodenale }\end{array}$ & $\begin{array}{l}\text { Strongyloidies } \\
\text { spp. }\end{array}$ & $\begin{array}{l}\text { Enterobius } \\
\text { spp. }\end{array}$ & $\begin{array}{l}\text { Trichostrogylus } \\
\text { spp. }\end{array}$ & $\begin{array}{l}\text { Schistosoma } \\
\text { mansoni }\end{array}$ & $\begin{array}{l}\text { Meloidogyne } \\
\text { spp. }\end{array}$ & $\begin{array}{l}\text { Radopholus } \\
\text { spp. }\end{array}$ & $\begin{array}{l}\text { Aphelencoidies } \\
\text { spp. }\end{array}$ & $\begin{array}{l}\text { Bayliascaris } \\
\text { spp. }\end{array}$ & $\begin{array}{l}\text { Toxocara } \\
\text { spp. }\end{array}$ & $\begin{array}{l}\text { Ancylostoma } \\
\text { canis }\end{array}$ & $\begin{array}{l}\% \\
\text { ( Total) }\end{array}$ \\
\hline Clay & 26.5 & 6.5 & 10.7 & $9(36)$ & 8 (32) & $2(8)$ & 0 & 0 & 0 & 0 & $4(16)$ & 0 & 0 & $1(4)$ & $1(4)$ & 0 & 25 (8.5) \\
\hline Loam & 27.5 & 6.2 & 14.9 & $58(30.6)$ & $32(16.9)$ & $26(13.8)$ & $10(5.2)$ & $9(4.7)$ & $4(2.1)$ & 2 (1) & $28(14.8)$ & $1(.5)$ & $1(.5)$ & $4(2.1)$ & $13(7.0)$ & 1 (.5) & $189(64.5)$ \\
\hline Sand & 27.7 & 6.2 & 12.6 & 25 (33) & $15(19.7)$ & $10(13.1)$ & $2(2.6)$ & $1(1.3)$ & $1(1.3)$ & 0 & $16(21)$ & 0 & 0 & 0 & $7(9.2)$ & $1(1.3)$ & 76 (26) \\
\hline $\begin{array}{l}(\%) \\
\text { Total }\end{array}$ & 27.2 & 6.3 & 12.7 & $92(31.4)$ & $55(19.5)$ & $38(12.9)$ & $12(4)$ & $10(3.4)$ & $5(1.6)$ & $2(.6)$ & $48(16.4)$ & $1(.3)$ & $1(.3)$ & $5(1.7)$ & $21(7.2)$ & $2(.6)$ & 293 \\
\hline
\end{tabular}


Table 3. Soil Physico-chemical parameters the in Emohua during the study

\begin{tabular}{lllll}
\hline Parameters & N & Mean & S.D & S.E \\
\hline Temperature $\left({ }^{\circ} \mathrm{C}\right)$ & 6 & 27.2 & 5.2 & 2.1 \\
pH & 6 & 6.3 & 2.5 & 1.0 \\
(\%) Organic matter & 6 & 12.7 & 3.6 & 1.4 \\
Clay & 32 & 16 & 4 & 0.7 \\
Loam & 233 & 115.5 & 10.7 & 0.7 \\
Sand & 95 & 47.5 & 6.9 & 0.6 \\
\hline
\end{tabular}

\section{DISCUSSION}

The results from the study indicated a prevalence of $(55 \%)$ of geohelminths in the soil samples in the study area with Loamy soil having the highest prevalence of $36.3 \%$. The prevalence in the samples was statistically significant as $(p<.05)$. Equally, a temperature of $27.2^{\circ} \mathrm{C}, \mathrm{pH}$ of 6.3 and $12.7 \%$ organic matter was recorded and 293 geohelminths recovered from the soil samples of the study area. The temperature of the soils in the area were slightly above room temperature which is suitable for development thriving of infective stages of geohelminths, The temperature ranges agree with $[1,31,32,33]$ who in their various findings agreed that the optimum temperature for the embryonation of soil transmitted helminthes eggs ranges from $16 \pm$ $1^{\circ} \mathrm{C}$ and $34 \pm 1^{\circ} \mathrm{C}$ and as the temperature increases within this range, the development of the egg is hastened. This might be due to the effect of heat to chemical reactions occurring inside the eggs for their development. Enzymes might be activated easily with higher temperature and molecules come in contact more often when excited due to the energy from heat. This is also evident in Ascaris eggs which were observed to halt development in freezing temperatures, which may be mainly due to the inhibition of the chemical reactions needed for the egg development $[31,33]$. The $\mathrm{pH}$ was slightly acidic tending towards the neutral point which is equally suitable for the development of the organisms. The $\mathrm{pH}$ ranges as observed is in line with studies which mentioned that helminth eggs are said to tolerate a large range of $\mathrm{pH}$. However, Ascaris suum eggs were said to have an arrested development when placed in an acidic environment. Hookworms, on the other hand, tolerate $\mathrm{pH}$ range of $4.6-9.4$ and will still be able to hatch and infect [34].

The organic carbon was equally high ensuring that there are enough nutrients for the survival of the different geohelminths soil dwelling stages. Though the organic matter in the soil types were almost at the same level, loamy soils had $14.9 \%$ organic content which is the highest and more of the geohelminthes recovered with the increase of the content of the organic matter (Table 2). Loamy soils equally has the ability to retain, nutrients, humusand moisture while still allowing excess water to drain away thereby giving the geohelminthes and other microorganisms access to oxygen for their survival. This is in line with work of Samia et al., [35] which revealed that there is a rise in the prevalence of geohelminths with the rise in the content of the organic matter.

Also the continuous seeding of the soil with the infective stages of these parasites through defaecation could also be responsible for this high prevalence of geohelminths. The significant presence of geohelminths infestation in this study conforms to the findings of $[25,32,33,36]$.

The soils in months of January- March had a prevalence of $52.9 \%$ while $47.1 \%$ prevalence was recorded between the months of April-June. This could be as a result of the moderate temperature and high organic contents of the soils in the months of January- March when compared to that of April-June (Fig. 1). While between the months of April-June, There was a slight decrease temperature and organic content which may have affected the number of organisms recovered. This finding is equally in agreement with [37] who recorded a prevalence of $(18.7 \%)$ and $(12.0 \%)$ respectively these months.

During the study period, Loamy soils had the highest prevalence of $64.5 \%$ of the organisms while clayey soils had the lowest prevalence of $8.5 \%$, this could be attributed to physicochemical parameters of Loamy soils which though were almost same with those of sandy and clayey soils had a higher organic content. It was equally observed that there was an increase in prevalence geohelminths in the soil types with an increase in the physico-chemical parameters. This is in line with the findings of Samia et al. [35].

Sandy and loamy soils are equally preferred by animals and indeed humans for defecation as they have loose texture for them to burrow their faeces deeper into the soil. Also, soil transmitted helminths eggs have been found to survive more in sandy soils, with high silt content, since they provide aeration and moisture for their development [9]. Clay soil had a very low prevalence which according to $[36,33]$ may be as 
a result of clayey soils not providing enough oxygen needed for soil transmitted helminthes egg development and are believed to prevent egg dispersal by water.

This agrees with the findings of [38] who reported that there is no direct relationship between soil texture and the prevalence of helminthes eggs in soil even though physical properties of soil do influence survival of eggs in the soil. The high prevalence of Ascaris lumbricoides, Trichuris trichuira and Meloidogyne spp, in this study may be as a result of them thrieving under different levels of physico-chemical parameters and soil types. Other studies in southern Nigeria stated that the high prevalence of the organisms may be as a result of their eggs being very resistant to harsh environmental conditions and can remain in the environment for longer period $[39,40]$. This result is also in line with results obtained by [41] in Anambra State eastern Nigeria and [25] in Rivers State. Trichuris spp prevalence of $19.5 \%$ was a bit higher when compared with reports from studies in other parts of the country which reported Trichuris prevalence to be $14.0 \%$ [40]. Hookworm had a prevalence of $12.3 \%$, this result is low compared with the values from other studies in various parts of the country which reported 22.5\%, 58.3\%, 29\% and $31.1 \%$ $[1,42,43]$. Table 3 indicates the parameters used in the study, Soil temperature mean $27.2^{\circ} \mathrm{C} \pm 5.2$ S.D, soil pH mean $6.3 \pm 2.5$ S.D and soil organic matter mean $12.7 \% \pm 3.6$ S.D, clay soil mean $16 \pm 3.5$ S.D, loam soil mean $115.5 \pm 10.7$ S.D and sandy soil mean $47.5 \pm 6.9$. Loamy soil had highest number of 233 samples, sandy soil had 95 samples, and clay had 32 samples. However, from the results the different parameters had some effect in the distribution of geohelminths.

\section{CONCLUSION}

An increase in the physico-chemical parameters of the soil samples especially the organic content lead to an increase in the abundance of geohelminthes in the various sites therefore combination of sanitation and community health education is a necessary and effective control measure of geohelminths. Sanitation by building of functional and accessible faecal disposal facilities that is suitable to the local conditions, as the only sure way of eradicating geohelminths especially those of public health importance remains the non deposition of human and other animal waste directly into the soils.

\section{RECOMMENDATIONS}

i. The communities should be enlightened on the dangers of open defecation.

ii. The Government should reintroduce sanitary inspection of our environment to check the indiscriminate and unhygienic disposal of human waste.

iii. Further studies should be carried out especially on children in the area to ascertain the level of geohelminths prevalence in humans.

\section{COMPETING INTERESTS}

Authors have declared that no competing interests exist.

\section{REFERENCES}

1. Amadi EC, Uttah EC. Impact of physicochemical factors of contaminated foci on the survival of geohelminths in Abua Communities, Niger Delta Nigeria. J. Appl. Sci. Environ. Manage. 2010;14(2):61-64.

2. Ettema $\mathrm{CH}$. Soil nematode diversity: species coexistence and ecosystem function. Journal of Nematology. 1998; 30:159-169.

3. Brussaard L, Behan-Pelleltier VM, Bignell $\mathrm{DE}$, et al. Biodiversity and ecosystem functioning in soil. Ambio. 1997;26:563570.

4. Chukwuma MC, Ekejindu IM, Agbakoba $\mathrm{NR}$, et al. The prevalence and risk factors of geohelminth infections among primary school children in Ebenebe Town, Anambra State, Nigeria. Middle-East Journal of Scientific Research. 2009;4(3): 211-215.

5. Yirgalem GH, Abraham D, Berhanu E. Prevalence of intestinal parasitic infections among children under five years of age with emphasis on Schistosoma mansoni in Wonji Shoa Sugar Estate, Ethiopia. Plos One. 2014;9(10):1371.

6. Pullan RL, Smith JL, Jasrasaria R. et al. Global numbers of infection and disease burden of soil transmitted helminth infections in 2010. Parasites \& Vectors. 2014;7:37.

7. Ziegelbauer K, Speich B, Mäusezah ID, et. al. Effect of sanitation on soiltransmitted Helminth infection: Systematic review and meta-analysis. Plos Med. 2012; 9(1):e1001162. 
8. De Silva, NR, Broker S, Hotez PJ, et al. Soil - transmitted helminths infections. Updating the global picture. Trends in Parasitology. 2003;19:547-557.

9. Hotez PJ, Brindley PJ, Bethony JM, et al. Helminth infections: The great neglected tropical diseases. J Clin Invest. 2008; 118:1311-1321.

10. Nicol JM, Turner SJ, Coyne DL, et al. Current nematode threats to world agriculture. In: Genomics and Molecular Genetics of Plant-Nematode Interactions (Jones, J.T., Gheysen, G. and Fenoll, C., eds), 21-44. Heidelberg: Springer; 2011.

11. Olabiyi TI, Olayiwola AO, Oyediran GO. Influence of soil textures on distribution of phytonematodes in the South Western Nigeria. World Journal of Agricultural Sciences. 2009;5(5):557-560.

12. John TJ, Annelies H, Etienne GJD, et al. Top 10 plant-parasitic nematodes in molecular plant pathology. Molecular Plant Pathology. 2013;14(9):946-961.

13. Olabiyi TI, Akanbi WB, Adepoju IO. Control of certain nematode pests with different organic manures on cowpea. American-Eurasian. J. Agric. Environ. Sci. 2007;2(5):523-527.

14. Uhuo CA, Nwanchor K, Umene DA, et al. Helminth parasites of fruits and vegetables planted in crop and landscape managent Garden College of Agricultural Sciences, Ebonyi State University abakaliki, Implication for Public Health. Journal of Biology, Agriculture and Healthcare. 2013; 3(9):9-11.

15. Crompton DWT, Savioli L. Intestinal Parasitic Infections and Urbanization. Bulletin of the World Health Organization 1993;71:1-7.

16. Phiri K, Whilty CLM, Graham SM. Urban/ rural differences in the prevalence and risk factors for intestinal helminth infection in Southern Malawi. J. Parasitol. 2002;18: 461-466.

17. Gupta VVSR Yeates. Soil microfauna as bioindicators of soil health. In Pankhurst, C., Doube, B. M., Soil health. New York, NY: CAB International. 1997;201-233.

18. Bear RJ. The relationship between Trichuris trichiura of man and Trchuris suis of the pig. Research in Veterinary Science. 1976;20:47-54.

19. Udonsi JK, Atata G. N. americanus. Effect of temperature, $\mathrm{pH}$., light and larval development, longevity and desiccation tolerance. Experimental Parasitology. 1987;63:136-142.

20. Smith G, Shadi GA. Ancylostoma duodenale and $N$. americanus: Effect of temperature on eggs development and mortality. Parasitology today 1990;99:127132.

21. Bundy DAP, Cooper ES. Trichuris and Trichuriasis in humans. Advances in Parasitology I. 1989;28:107-173.

22. Otto GF. A study of the moisture requirement of the eggs of the home dog, humans and pig Ascaris. American Journal of Hygiene. 1999;10:497-520.

23. Bethony J. Soil-transmitted helminth infections: Ascariasis, Trichuriasis, and Hookworm. Lancet. 2006;6;367(9521): 1521-32..

24. Wikipedia Emohua; 2009.

Available:www.wikipedia.org

25. Eze NC, Owhoeli O, Oweh O. Prevalence of human infecting geohelminths in soil found around refuse dumpsites in Emohua Local Government Area of Rivers State, South-South, Nigeria. Asian Journal of Biology. 2016;1(1):1-7.

26. Storer DA, A simple high sample volume ashing procedure for determination of soil organic matter. Comm. Soil Science and Plant Analysis. 1984;15:759-772.

27. Worku S, Solomon GS. Sanitary survey of residential areas using Ascaris lumbricoidesova as indicators of environmental hygiene, Jimma, Ethiopia Ethiop. J. Health Dev. 2007;21(1):18-24.

28. Cheesbrough $M$. District laboratory Practice in tropical Countries, Part 1 $\left(2^{\text {nd }} e d\right)$. Cambridge University Press. 2005; 194-202.

29. James GB, Manuel MO, Paul DL, Irma T DL. Identification of plant-parasitic nematodes. Comstock publishing associates Ithaca and London; 2011.

30. Thrushfield DM. Veterinary epidemiology. Blackwell Science, UK; 1995.

31. Arene FOI. Ascaris suum: Influence of embryonation temperature on the viability of the infective larva. Journal of Thermal Biology. 1986;11(1)9-15.

32. Hotez PJ, Bethony J, Bottazzi ME, et al. Hookworm: The great infection of mankind. Plos Med. 2005;2(3):67.

33. Vachel G. Paller V. and Emmanuel RC. Toxocara (Nematoda: Ascaridida) and Other Soil-Transmitted Helminth Eggs contaminating soils in selected Urban and Rural Areas in the Philippines. Hindawi 
Publishing Corporation Scientific World Journal. 2014;1-6

34. WHO. Integrated Guide to Sanitary Parasitology, WHO Regional Office for the Eastern Mediterranean; 2004. ISBN 92-9021-386

35. Samia E, Etewa, Sara A. Abdel-Rahman, et al. Geohelminths distribution as affected by soil properties, physicochemical factors andclimate in Sharkyia governorate Egypt. Journal of Parasitic Diseases. 2014;40(2): 496-504

36. Mazgajska H. Eggs of Toxocara spp in the environment and their public health implications. Journal of Helminthology. 2001;75:147-151.

37. Nwoke EU, Ibiam GA, Odikamnoro $O O$ et al. Examination of soil samples for the incidence of geohelminth parasites in Ebonyi north-central area of Ebonyi State, south-east of Nigeria. Archives of Applied Science Research. 2013;5(6):41-48.

38. Mazgajska $H$. The role of some environmental factors in the contamination of soil with Toxocara spp. and other geohelminth eggs. Parasitology International. 1997;46:67-72.
39. Ogbe MN, Edet EE, Isichel NN. Intestinal Helminth infection in primary school children in areas of operation of Shell Petroleum Development Company Nigeria (SPDC) western division in Delta State. The Nig J. Parasitol. 2002;23:3-10.

40. Anosike JC, Chighana JI, Nwoke BEB, et al. A survey of intestinal parasites among school children of post primary institution in Imo state, $28^{\text {th }}$ annual conference Abstract (63). Nigeria. Soc. Parasitol. 2002;20:74.

41. Egwuyenga OA, Ataikuru DP, Nmorsi QPG. Studies on the intestinal helminthes infection in Eku, Delta State. Nig. Soc. Parasitol. 2004;20:24-30.

42. Obiukwu MO, Umeanaeto PU, Eneanya $\mathrm{Cl}$. et al. Prevalence of gastrointestinal Helminth in School Children in Mbaukwu Anambra State, Nigeria. Annal of tropical Medicine and Parasitology. 2008;101:705713.

43. Chukwuma MC, Ekejindu IM, Agbakoba $\mathrm{NR}$, et al. The prevalence and risk factors of Geohelminth infections among primary school children in Ebenebe Town, Anambra state Nigeria. Middle-East J. Sc. Res. 2009;4(3):211-215.

(c) 2017 Ovutor et al.; This is an Open Access article distributed under the terms of the Creative Commons Attribution License (http://creativecommons.org/licenses/by/4.0), which permits unrestricted use, distribution, and reproduction in any medium, provided the original work is properly cited.

Peer-review history:

The peer review history for this paper can be accessed here: http://sciencedomain.org/review-history/19915 